\title{
Recombinant Human Thyrotropin in Thyroid Cancer and Hypopituitarism Due to Sella Metastasis
}

\author{
JÖRN H. RISSE, ${ }^{1}$ FRANK GRÜNWALD, ${ }^{1}$ HANS BENDER, ${ }^{1}$ HEINRICH SCHÜLLER, ${ }^{2}$ \\ DIRK VAN ROOST, ${ }^{3}$ and HANS-JÜRGEN BIERSACK ${ }^{1}$
}

\begin{abstract}
We present a patient with thyroid cancer and hypopituitarism who required recombinant human thyrotropin (rhTSH) for ${ }^{131}$ I scanning with respect to subsequent therapy. The thyroid cancer had been unknown until central neurological symptoms developed, leading to the diagnosis of a huge metastasis to the sella that was the only manifestation of metastatic spread. The failure to generate endogenous thyrotropin (TSH) was overcome by the use of rhTSH for performing a ${ }^{131}$ I test. Unfortunately, the ${ }^{131}$ I uptake was not sufficient for therapy. This subject is the first reported case who required the application of rhTSH due to a single thyroid cancer metastasis in the sella region with secondary failure to generate endogenous TSH.
\end{abstract}

\section{INTRODUCTION}

M ETASTATIC THYROID CANCER with iodide transport activity should be treated by radioiodine. For optimal sensitivity of the ${ }^{131}$ I uptake test and maximal therapeutic uptake, stimulation of any residual thyroid tissue by high thyrotropin (TSH) levels is required (1). This has usually been achieved by thyroid hormone withdrawal causing severe hypothyroidism (2). The application of recombinant human thyrotropin ( $\mathrm{rhTSH}$ ) instead of hormone withdrawal has been shown to be safe and effective $(3,4)$. In this article, we report (1) the first case of a huge single thyroid cancer metastasis to the sella and (2) the usefulness of rhTSH in a case with failure to generate endogenous TSH.

\section{CASE REPORT}

A 68-year-old woman presented with severe vision loss that had been developing for the past 8 months. She gave a history of frontal accentuated headaches that had been progressive for 3 years. In the last 2 years she experienced additional diplopia in varying grades. Recently, a personality change occurred with increased communicativeness, being hot-tempered, and sometimes confused. She reported four thyroid operations between 1982 and 1994 in Kazakhstan; no diagnosis or histological findings were available. She had no hormone substitution or therapy.
On physical examination, the sight was reduced to finger recognition on the right and to movement vision on the left eye. Her voice was aphonic; no other neurological defects were detected. Magnetic resonance imaging (MRI) revealed a large solid tumor in the sella region with destruction of the surrounding osseous structures, and the optic chiasm was no longer identifiable (Fig. 1). There was no diabetes insipidus, but the anterior pituitary function tests revealed hypopituitarism (Table 1). Preoperatively, various stimulation tests for the pituitary function reserve were performed (details given in Table 1). The tentative diagnosis was pituitary adenoma with the differential diagnoses of chordoma, chondroma or meningioma.

To obtain a rapid decompression of the optic nerves and chiasm, transsphenoidal surgery was done as a first-step procedure. Only partial resection of the sella tumor could be performed because of the difficult approach and excessive intraoperative bleeding. The histopathological examination yielded a highly differentiated adenocarcinoma with colloid containing follicles; there were no signs of increased proliferative activity. Immunostaining was negative for adrenocorticotrophic hormone (ACTH), growth hormone $(\mathrm{GH})$, follicle-stimulating hormone (FSH), luteinizing hormone (LH), prolactin, and TSH, but positive for thyroglobulin, leading to the diagnosis of thyroid cancer metastasis.

The patient was referred to the nuclear medicine department to evaluate the possibility of radioiodine therapy.

Departments of ${ }^{1}$ Nuclear Medicine, ${ }^{2}$ Radiology, and ${ }^{3}$ Neurosurgery, University Hospital of Bonn, Bonn, Germany. 


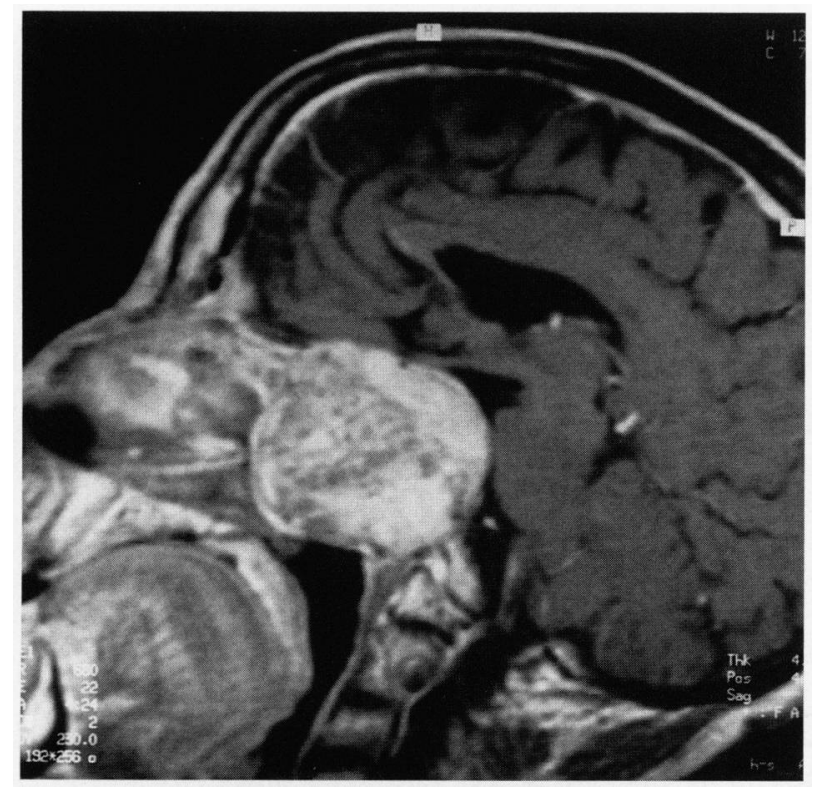

FIG. 1. Sagittal T1-weighted magnetic resonance imaging (MRI) of the skull after intravenous administration of gadolinium. The tumor in the sella region is approximately $5 \mathrm{~cm}$ in diameter, shows inhomogeneous contrast enhancement, and destroys the sella walls and clivus. The ethmoidal cells are full of tumor tissue, the cavernous sinuses are infiltrated, and the optic chiasm is highly compressed (not distinguishable).

The thyroglobulin (hTG) level in serum (as measured by ${ }^{125}$ I immunoradiometric assay (IRMA) and validated by recovery test) was $3681 \mathrm{ng} / \mathrm{mL}$. Sonography of the neck region showed $3 \mathrm{~mL}$ of thyroid remnant tissue on the left side and none on the right. A whole-body scintigraphy with ${ }^{99 \mathrm{~m}} \mathrm{Tc}$-sestamibi revealed significant tracer accumulation in the sella and some activity in the thyroid region, due to remnant tissue (Fig. 2). A whole-body positron emission tomography with ${ }^{18}$ fluorodeoxyglucose (18 FDG-PET) showed an increased glucose metabolism in the sella tumor without evidence of any other suspicious regions; the thyroid bed region particularly, showed no pathological finding. Hence, the sella tumor represented the only localization of malignancy. Because of the poor clinical condition of the patient, we decided not to perform an ablative large-dose radioiodine therapy initially, but rather first to check the radioiodine uptake in the sella tumor. Because the radioiodine test requires high TSH levels and the patient failed to produce endogenous TSH, we applied rhTSH (Thyrogen $^{\text {TM }}$, Genzyme B.V., Naarden, NL) 0.9 mg intramuscularly 48 hours and 24 hours prior to radioiodine administration after having obtained written informed consent. The result was an increase of the TSH level (in serum, as measured by ${ }^{125}$ I-IRMA) from 0.16 to $237 \mathrm{mU} / \mathrm{L} 24$ hours after the first rhTSH administration; after 48 hours, following this first administration (24 hours after the second), TSH was $230 \mathrm{mU} / \mathrm{L}$. Serum h-TG increased in parallel to 4166 and its maximum value of $6626 \mathrm{ng} / \mathrm{mL} 24$ and 48 hours after the first rhTSH administration. No side effects occurred. For the radioiodine test, $2 \mathrm{mCi}(74 \mathrm{MBq}$ ) of ${ }^{131}$ I were given intravenously. In the probe measurement, the thyroid showed an uptake of $8 \%$ after 24 hours. In contrast, the radioiodine uptake in the sella tumor was less than $0.5 \%$ after 24 hours. Therefore, no significant tumor doses could be expected from radioiodine therapy.

Consequently, the patient was treated by external radiation of the sella region with $23 \mathrm{MV}$ photon beam therapy up to a total dose of $45 \mathrm{~Gy}$. Thyroxine substitution and hydrocortisone therapy was begun. After 4 months, clinical examination, MRI and ${ }^{99 \mathrm{~m}} \mathrm{Tc}$-sestamibi scintigraphy showed stable disease; hTG had decreased to 574 $\mathrm{ng} / \mathrm{mL}$.

\section{DISCUSSION}

The pituitary gland is a relatively uncommon site for secondary involvement in patients who died from disseminated metastatic cancer (5). As reliable radiographic or clinical distinction between a pituitary metastasis and primary adenoma is not possible, surgical exploration for biopsy and decompression is essential, unless precluded by

Table 1. Anterior Pituitary Stimulation Tests

\begin{tabular}{|c|c|c|c|c|c|c|c|c|}
\hline & Pretest & Normal range & 0 minutes & 15 minutes & 30 minutes & 60 minutes & $\begin{array}{l}\text { Expected } \\
\text { increase }\end{array}$ & Units \\
\hline Estradiol & 6.9 & $<46$ & & & & & & $\mathrm{pg} / \mathrm{mL}$ \\
\hline $\mathrm{FT}_{3}$ & 1.28 & $2.0-5.1$ & & & & & & $\mathrm{pg} / \mathrm{mL}$ \\
\hline $\mathrm{FT}_{4}$ & 0.52 & $0.9-1.9$ & & & & & & $\mathrm{ng} / \mathrm{dL}$ \\
\hline TSH & 0.2 & $0.27-4.2$ & 0.2 & & 0.28 & & $3-25$ & $\mathrm{mU} / \mathrm{L}$ \\
\hline ACTH & $<5.0$ & $9-52$ & $<5.0$ & 49 & 79 & 78 & & $\mathrm{pg} / \mathrm{mL}$ \\
\hline Cortisol & 2.5 & $8-25$ & 2.1 & 2.2 & 5.6 & 7.3 & $>7$ & $\mu \mathrm{g} / \mathrm{dL}$ \\
\hline LH & $<0.1$ & $>15$ & $<0.1$ & & $<0.1$ & 0.1 & $\times 2$ & IU/L \\
\hline FSH & 0.7 & $>15$ & 0.7 & & 1.2 & 1.7 & $\times 1.5$ & $\mathrm{IU} / \mathrm{L}$ \\
\hline $\mathrm{hGH}$ & 0.2 & $<3$ & 0.2 & & 2.2 & 5.8 & $>10$ & $\mathrm{ng} / \mathrm{mL}$ \\
\hline Prolactin & 91.9 & $3.9-27.7$ & 79.2 & & & 92.7 & & $\mathrm{ng} / \mathrm{mL}$ \\
\hline
\end{tabular}

For her anterior pituitary stimulation tests, the patient was given $50 \mu \mathrm{g}$ of GHRH (GHRH Ferring, Ferring), $100 \mu \mathrm{g}$ of CRH (CRH Ferring, Ferring), and $100 \mu \mathrm{g}$ of GnRH (Relefact LH-RH, Hoechst) intravenously at 9:40 A.M. The next day, at 9:00 A.M., the patient was given $200 \mu \mathrm{g}$ of TRH (Antepan, Henning) intravenously. Detailed stimulation test results are given (all in serum).

$\mathrm{FT}_{3}$, free triiodothyronine; $\mathrm{FT}_{4}$, free thyroxine; TSH, thyrotropin; ACTH, adrenocorticotrophic hormone; $\mathrm{LH}$, luteinizing hormone; FSH, follicle stimulating hormone; hGH, human growth hormone. 


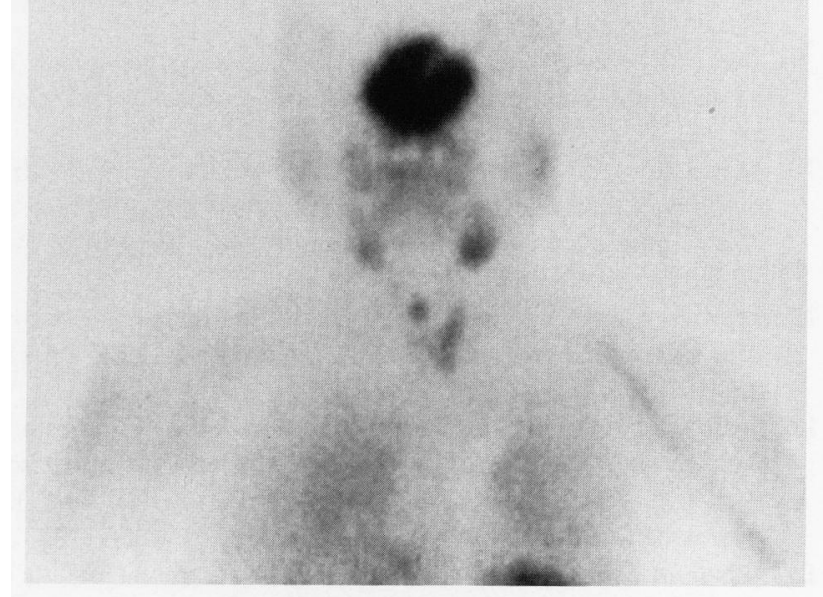

FIG. 2. Anterior ${ }^{99 \mathrm{~m} T c-s e s t a m i b i}$ scintigraphy showing increased uptake in the sella tumor. Note normal uptake in salivary glands and thyroid remnant.

widespread coexistent disease (5). In this case, the mass might have been an aggressive pituitary adenoma that had dedifferentiated and begun to display thyroid morphological features; one might argue that there is no pathological evidence that this patient had a primary thyroid carcinoma. It is true that a primary thyroid cancer cannot be proven because it has probably been removed during one of the preceding operations, and it was impossible to gather the pertinent information in Kazakhstan. In contrast to this, not only the histopathological examination of sella tumor tissue yielded morphological features of thyroid tissue, but moreover, immunostaining was positive for hTG, leading to the diagnosis of a thyroid cancer metastasis.

Thyroid cancer is well known to metastasize to the lungs and bones, whereas the brain is involved in only $1 \%-2 \%$ $(6,7)$. The brain as the only distant metastatic site was identified in less than $0.1 \%$ of thyroid cancer patients (7). With respect to the pituitary gland, there are only few reports with documentation of metastases from carcinoma of the thyroid (8-11). As known from cancers other than thyroid, a metastasis to the sella turcica may even be the first and only manifestation of an otherwise unknown cancer (5). To our knowledge, this is the first report of a huge single thyroid cancer metastasis in the sella region without evidence of further metastases, as shown by positron emission tomography (PET).

Thyroid cancer with affinity to iodine should be treated with radioiodine; the iodine uptake correlates with the differentiation grade and prognosis of the tumor (1). Because the tumor tissue in the present case was well differentiated, a significant radioiodine uptake was expected. The tumor proved to exert high ${ }^{18} \mathrm{FDG}$ - and ${ }^{99} \mathrm{~m}$ Tc-sestamibi uptake that may agree with either negative or positive results for the radioiodine test (12). Together with the histological findings, there was a chance for a positive radioiodine test that would have led to radioiodine therapy as the best therapeutic option for this patient.
One might argue that we should have used a therapeutic dose of ${ }^{131}$ I to assess whether the metastasis was able to take up radioiodine for two reasons. First, in case of a rather large thyroid residue, it is not unusual that a concomitant metastasis does not take up enough radioiodine to be visualized and treated, so one should first ablate the thyroid remnant before assuming that a metastasis is not able to take up radioiodine. Second, diagnostic doses of ${ }^{131}$ I may not be sufficient to visualize metastases with lowiodine avidity, while they can be better detected by the administration of therapeutic doses followed by whole body scans $(6,13,14)$. We were aware of these facts, but our case was particularly different in some instances. First, the metastasis volume exceeded the thyroid residue, which was rather small. Second, we did not perform a whole-body scan, but rather, performed probe measurements, which are much more sensitive. Third, the patient was in such poor clinical condition that only the least possible burden of diagnostic or therapeutic procedures was tolerable and appropriate. Fourth, in this case, we used $2 \mathrm{mCi}$ of ${ }^{131} \mathrm{I}$ intravenously as the diagnostic dose, which is much more than the usual test dose of $0.1 \mathrm{mCi}$ given orally. This was done to yield a better diagnostic sensitivity within a lowdose diagnostic range. Due to the German radiation protection laws, higher activities could not be applied on an outpatient basis. As long as it was uncertain that the patient would receive radioiodine therapy, we wanted her to be studied on an outpatient basis. Finally, during the test, the thyroid remnant showed an uptake of only $8 \%$, so there was $92 \%$ remaining for uptake in the large sella tumor, which was less than $0.5 \%$.

A main prerequisite for a positive radioiodine test (and thus an effective therapy) are elevated basal TSH-levels. This is usually achieved by thyroxine withdrawal, which has two main side effects: severe symptomatic hypothyroidism and stimulation of tumor cell growth due to persistent increased TSH release $(1,2)$. Recombinant human thyrotropin (rhTSH) was developed mainly to raise the TSH level without thyroxine withdrawal $(3,15)$. In our patient, rhTSH became necessary because of hypopituitarism due to her sella metastasis. We performed the rhTSH test according to the modalities described in the literature $(3,4)$; in these studies, a significant increase of the TSH levels was achieved, and the radioiodine scans were mostly comparable to those achieved in hypothyroidism. In our patient, a significant increase of the TSH level was achieved as well. The increase of the hTG level was also as expected from the literature $(3,4)$. With respect to $\mathrm{rhTSH}$ application in the combination of metastatic thyroid cancer and secondary hypothyroidism, there are few other reports in the literature (16-18), but none of these cases had a sella metastasis causing their hypopituitarism.

Unfortunately, there was not sufficient radioiodine uptake in our patient's sella tumor. This is consistent with the finding that particularly ${ }^{18} \mathrm{FDG}$ - and ${ }^{99 \mathrm{~m}} \mathrm{Tc}$-sestamibi-positive tumors are frequently radioiodine negative (12). In that study population, there was another tendency that ${ }^{18} \mathrm{FDG}$-positive and radioiodine-negative tumors were encountered in high-grade tumors, whereas radioiodinepositive and ${ }^{18}$ FDG-negative tumors were found in lowgrade carcinomas, although no statistical significance could be reached (12). The presented case ( ${ }^{18} \mathrm{FDG}$ - and ${ }^{99 \mathrm{~m} T \mathrm{~T}-}$ 
sestamibi-positive, radioiodine-negative, but highly differentiated tumor tissue) did not meet all of these criteria. Fortunately, the disease was stable after external photon beam therapy, and the h-TG level had even decreased.

This case illustrates two major points. When confronted with a large sella tumor, the physician should be aware of the possibility of a pituitary metastasis, although this is an uncommon sequelae of cancer. A metastasis to the sella turcica may even be the first and only manifestation of an otherwise unknown cancer. Of course, for thyroid cancer, this is extremely rare. In a case of the combination of thyroid cancer and failure to generate endogenous TSH, the use of rhTSH may permit an effective radioiodine test.

\section{ACKNOWLEDGMENT}

We thank Prof. Klingmüller, M.D., Department of Endocrinology, University of Bonn for the data of the anterior pituitary function tests.

\section{REFERENCES}

1. Hershman JM, Blahd WH, Gorden ME 1990 Thyroid gland. In: Haskell CM (ed) Cancer Treatment. Saunders, Philadelphia, p 406-414.

2. Dow KH, Ferrell BR, Anello C 1997 Quality-of-life changes in patients with thyroid cancer after withdrawal of thyroid hormone therapy. Thyroid 7:613-619.

3. Meier CA, Braverman LE, Ebner SA, Veronikis I, Daniels GH, Ross DS, Deraska DJ, Davies TF, Valentine M, DeGroot LJ, Curran P, McEllin K, Reynolds J, Robbins J, Weintraub BD 1994 Diagnostic use of human recombinant thyrotropin in patients with thyroid carcinoma (phase I/II study). J Clin Endocrinol Metab 78:188-196.

4. Ladenson PW, Braverman LE, Mazzaferri EL, Brucker-Davis F, Cooper DS, Garber JR, Wondisford FE, Davies TF, DeGroot LJ, Daniels GH, Ross DS, Weintraub BD 1997 Comparison of administration of recombinant human thyrotropin with withdrawal of thyroid hormone for radioactive iodine scanning in patients with thyroid carcinoma. N Engl J Med 337:888-896.

5. Branch CL Jr, Laws ER Jr 1987 Metastatic tumors of the sella turcica masquerading as primary pituitary tumors. J Clin Endocrinol Metab 65:469-474.

6. Schlumberger MJ 1998 Papillary and follicular thyroid carcinoma. N Engl N Med 338:297-306.

7. Chiu AC, Delpassand ES, Sherman SI 1997 Prognosis and treatment of brain metastases in thyroid carcinoma. I Clin Endocrinol Metab 82:3637-3642.

8. Sziklas JJ, Mathews J, Spencer RP, Rosenberg RJ, Ergin MT, Bower BF 1985 Thyroid carcinoma metastatic to pituitary. J Nucl Med 26:1097.

9. Teears RJ, Silverman EM 1975 Clinicopathologic review of 88 cases of carcinoma metastatic to the pituitary gland. Cancer 36:216-220.

10. McCarthy DJ, Karsner HT 1912 Adenocarcinoma of the thyroid, with metastasis to the cervical glands and pituitary: A contribution to the pathology of abnormal fat formation. Am J Med Sci 144:834.

11. Johnson PM, Atkins HL 1965 Functioning metastasis of thyroid carcinoma in sella turcica. I Clin Endocrinol Metab 25:1122.

12. Grünwald F, Menzel C, Bender H, Palmedo H, Willkomm P, Ruhlmann J, Franckson T, Biersack H-J 1997 Comparison of ${ }^{18} \mathrm{FDG}$-PET with ${ }^{131}$ Iodine and ${ }^{99 \mathrm{~m}} \mathrm{Tc}$-sestamibi scintigraphy in differentiated thyroid cancer. Thyroid 7:327-335.

13. Cavalieri RR 1996 Nuclear imaging in the management of thyroid carcinoma. Thyroid 6:485-492.

14. Rudavsky AZ, Freeman LM 1997 Treatment of scan-negative, thyroglobulin-positive metastatic thyroid cancer using radioiodine ${ }^{131} I$ and recombinant human thyroid stimulating hormone. J Clin Endocrinol Metab 82:11-14.

15. Thotakura NR, Desai RK, Bates LG, Cole ES, Pratt BM, Weintraub BD 1991 Biological activity and metabolic clearance of a recombinant human thyrotropin produced in Chinese hamster ovary cells. Endocrinology 128:341-348.

16. Ringel MD, Ladenson PW 1996 Diagnostic accuracy of ${ }^{131} I$ scanning with recombinant human thyrotropin versus thyroid hormone withdrawal in a patient with metastatic thyroid carcinoma and hypopituitarism. J Clin Endocrinol Metab 81:1724-1725.

17. Luster M, Reinhardt W, Körber C, Hänscheid H, Rendl J, Mann K, Reiners C 1997 Use of recombinant human TSH in a patient with metastatic follicular thyroid carcinoma and secondary hypothyroidism. J Endocrinol Invest 20(suppl 5):54.

18. Adler ML, Macapinlac HA, Robbins RJ 1998 Radioiodine treatment of thyroid cancer with the aid of recombinant human thyrotropin. Endocr Pract 4:282-286.

Address reprint requests to: Dr. Jörn H. Risse Dept. of Nuclear Medicine University Hospital of Bonn Sigmund-Freud-Str. 25 53105 Bonn Germany

E-mail: JRisse@mailer.meb.uni-bonn.de 


\section{This article has been cited by:}

1. Joanna Klubo-Gwiezdzinska, Kenneth D. Burman, Douglas Van Nostrand, Mihriye Mete, Jacqueline Jonklaas, Leonard Wartofsky. 2013. Potential Use of Recombinant Human Thyrotropin in the Treatment of Distant Metastases in Patients with Differentiated Thyroid Cancer. Endocrine Practice 1:-1, 1-26. [CrossRef]

2. Joanna Klubo-Gwiezdzinska, Kenneth D. Burman, Douglas Van Nostrand, Mihriye Mete, Jacqueline Jonklaas, Leonard Wartofsky. 2012. Radioiodine Treatment of Metastatic Thyroid Cancer: Relative Efficacy and Side Effect Profile of Preparation by Thyroid Hormone Withdrawal Versus Recombinant Human Thyrotropin. Thyroid 22:3, 310-317. [Abstract] [Full Text HTML] [Full Text PDF] [Full Text PDF with Links]

3. Marcus Middendorp, Frank Grünwald. 2010. Update on Recent Developments in the Therapy of Differentiated Thyroid Cancer. Seminars in Nuclear Medicine 40:2, 145-152. [CrossRef]

4. Martin Schlumberger, Isabelle Borget, G\&eacute;rard De Pouvourville, Furio Pacini. 2007. Recombinant Human ThyroidStimulating Hormone: Use in Papillary and Follicular Thyroid Cancer. Hormone Research 67:1, 132-142. [CrossRef]

5. Richard J. Robbins, Albert Driedger, James Magner. 2006. Recombinant Human Thyrotropin-Assisted Radioiodine Therapy for Patients with Metastatic Thyroid Cancer Who Could Not Elevate Endogenous Thyrotropin or Be Withdrawn from Thyroxine. Thyroid 16:11, 1121-1130. [Abstract] [Full Text PDF] [Full Text PDF with Links]

6. Whitney W. Woodmansee, Bryan R. Haugen. 2004. A review of the potential uses for recombinant human TSH in patients with thyroid cancer and nodular goiter. Clinical Endocrinology 61:2, 163-173. [CrossRef]

7. NURIYE ÖZLEM KÜÇÜK, PELIN ARCAN, GÜLSEREN ARAS, KEMAL METIN KR. 2002. A Hypophyseal Metastasis of Follicular Thyroid Carcinoma. Clinical Nuclear Medicine 27:4, 309-310. [CrossRef]

8. G. Pellegriti, C. Scollo, D. Giuffrida, R. Vigneri, S. Squatrito, V. Pezzino. 2001. Usefulness of Recombinant Human Thyrotropin in the Radiometabolic Treatment of Selected Patients with Thyroid Cancer. Thyroid 11:11, 1025-1030. [Abstract] [Full Text PDF] [Full Text PDF with Links] 